\title{
Relationships between Surface Properties and Snow Adhesion and Its Shedding Mechanisms
}

\author{
Jamie Heil ${ }^{1}$, Behrouz Mohammadian ${ }^{1}$ (), Mehdi Sarayloo ${ }^{2}$, Kevin Bruns ${ }^{1}$ \\ and Hossein Sojoudi 1,*(D) \\ 1 Department of Mechanical, Industrial and Manufacturing Engineering, University of Toledo, Toledo, \\ OH 43606, USA; Jamie.Heil@rockets.utoledo.edu (J.H.); Behrouz.Mohammadian@utoledo.edu (B.M.); \\ Kevin.Bruns@rockets.utoledo.edu (K.B.) \\ 2 Department of Civil and Environmental Engineering, University of Toledo, Toledo, $\mathrm{OH} 43606$, USA; \\ Mehdi.Sarayloo@rockets.utoledo.edu \\ * Correspondence: hossein.sojoudi@utoledo.edu
}

Received: 8 July 2020; Accepted: 29 July 2020; Published: 5 August 2020

\begin{abstract}
Understanding the mechanisms of snow adhesion to surfaces and its subsequent shedding provides means to search for active and passive methods to mitigate the issues caused by snow accumulation on surfaces. Here, a novel setup is presented to measure the adhesion strength of snow to various surfaces without altering its properties (i.e., liquid water content (LWC) and/or density) during the measurements and to study snow shedding mechanisms. In this setup, a sensor is utilized to ensure constant temperature and liquid water content of snow on test substrates, unlike inclined or centrifugal snow adhesion testing. A snow gun consisting of an internal mixing chamber and ball valves for adjusting air and water flow is designed to form snow with controlled LWC inside a walk-in freezing room with controlled temperatures. We report that snow adheres to surfaces strongly when the LWC is around $20 \%$. We also show that on smooth (i.e., RMS roughness of less than $7.17 \mu \mathrm{m}$ ) and very rough (i.e., RMS roughness of greater than $308.33 \mu \mathrm{m}$ ) surfaces, snow experiences minimal contact with the surface, resulting in low adhesion strength of snow. At the intermediate surface roughness (i.e., RMS of $50 \mu \mathrm{m}$ with a surface temperature of $0{ }^{\circ} \mathrm{C}$, the contact area between the snow and the surface increases, leading to increased adhesion strength of snow to the substrate. It is also found that an increase in the polar surface energy significantly increases the adhesion strength of wet snow while adhesion strength decreases with an increase in dispersive surface energy. Finally, we show that during shedding, snow experiences complete sliding, compression, or a combination of the two behaviors depending on surface temperature and LWC of the snow. The results of this study suggest pathways for designing surfaces that might reduce snow adhesion strength and facilitate its shedding.
\end{abstract}

Keywords: snow formation; snow adhesion; snow gun; surface roughness; surface energy; liquid water content (LWC) sensor

\section{Introduction}

The freezing process of liquid water droplets in the atmosphere and adhering to surfaces is known as atmospheric icing [1,2]. Atmospheric icing includes the three important categories: hoar frost, in-cloud icing, and precipitation icing [3]. Hoar frost forms because of the direct phase change of water vapor around a cold substrate to the solid state of ice. On the other hand, in-cloud icing occurs when supercooled water droplets convert to ice. In-cloud icing includes two phases: glaze and rime [2]. Glaze particles have a diameter of $70 \mu \mathrm{m}$ to a few millimeters and occur when there is water runoff from a surface. Rime particles have a diameter of 5-70 $\mu \mathrm{m}$ and occur when there is no water runoff 
from the surface [4,5]. Precipitation icing includes freezing rain, and snow [6]. Freezing rain occurs when supercooled water droplets freeze upon impact to a surface [6,7]. Snow, due to its high stickiness and capability of applying high loads to structures, can be problematic.

Snow events occur naturally in many areas in the world such as North America, Europe, Russia, Japan, Greenland, and others. Safety concerns arise when snow accretes on bridge cables, power lines, telecommunication structures, wind turbines, sensors of autonomous vehicles, and solar panels. Snow accretion on structures can result in failures due to overloading, while its shedding and detachment could be damaging to pedestrians and vehicles $[2,8]$. Snow covering the sensors of autonomous vehicle sensors causes loss of data to the system, which could lead to fatal vehicular accidents $[9,10]$. Solar panels experience a significant reduction in power production when covered with snow, which sometimes may last for days [11-13].

It was initially reported that snowfall occurs when wet bulb temperatures are below $0{ }^{\circ} \mathrm{C}$ and moisture is present in the atmosphere [14]. Later findings indicated snow formation even at wet bulb temperatures greater than $0{ }^{\circ} \mathrm{C}$ [15]. Snow particles are formed in clouds as a result of nucleation of water droplets around small particles. The most observed snow particle structures are plate-like, columnar, needle, and dendritic. The size and shape of the snow particles are dependent on the temperature and supersaturation of the environment [16].

A snow layer is a mixture of ice particles, air, and water. Liquid water content (LWC) is a snow property that describes the amount of water in the snow and is defined by the mass ratio of the liquid water in the snow to the total mass of snow [17]. Dry snow is composed of air and ice. Wet snow on the other hand has water that fills the gaps between the ice particles, minimizing the amount of air between these particles. Dry snow has a relatively low density, rarely exceeding $100 \mathrm{~kg} / \mathrm{m}^{3}$ [8]. Snow is in so-called pendular regime, when the liquid water content in snow is below $\sim 27 \%$. Air and small amounts of water fill the gaps between the ice particles. The so-called funicular regime occurs when gaps between ice particles are mostly filled by liquid water with minimal air [18]. Dry snow can accumulate at wind speeds below $2 \mathrm{~m} / \mathrm{s}$ and below $0{ }^{\circ} \mathrm{C}$, in which case air accounts for more than $70 \%$ of the total volume and the liquid water content is typically less than $5 \%$ [19]. Wet snow results when dry snowflakes rapidly metamorphize at negative air temperatures in supercooled clouds. These snowflakes pass into a positive temperature air layer, allowing melting to occur, thus causing an increase in the liquid water content [20].

Discrepancies exist about at which temperatures wet snow actually forms. Admirat claimed wet snow forms in the temperature range of 0 to $2{ }^{\circ} \mathrm{C}$ [2]. However, Makkonen later claimed that snow accretes at wet bulb temperatures greater than $0{ }^{\circ} \mathrm{C}$ [15]. Next, he modified this claim to wet bulb temperatures greater than $-0.2^{\circ} \mathrm{C}$ [21]. Finstead and co-workers also suggested that wet snow occurs when air temperatures are between -2 and $5{ }^{\circ} \mathrm{C}$ and the critical percent relative humidity is more than $85.1-5.3 \times \mathrm{T}_{\mathrm{a}}$ [22]. Under these conditions snow can adhere to surfaces. At the first stages of snow accumulation, it is relatively easy to remove the snow, but once the temperature falls below $0{ }^{\circ} \mathrm{C}$, the snow freezes into a hard, dense $\left(300-800 \mathrm{~kg} / \mathrm{m}^{3}\right)$ layer with strong adhesion [2]. While some studies have aimed at exploring snow formation and adhesion [5,23-25] there is no comprehensive study focusing on relationships between surface properties and snow adhesion and its shedding mechanisms.

Here, we present a systematic approach to investigate the impact of surface energy and roughness on the adhesion strength and shedding mechanism of snow. An experimental setup is developed to measure snow adhesion strength on various surfaces without altering the properties of snow (i.e., liquid water content). A LWC sensor is used to monitor the snow wetness during the adhesion measurements. We show how infiltration of the snow's free liquid water into the surface roughness depends on temperature and plays a significant role in snow adhesion or shedding. The results of this work can be helpful in identifying snow mitigation strategies on bridge cables, solar panels, and camera lenses of autonomous vehicles. 


\section{Experimental Section}

A snow gun was designed for artificial snow formation year-round inside a walk-in freezing room that reached temperatures of $-20^{\circ} \mathrm{C}$ (Figure S1) [26]. The snow gun has an internal mixing chamber and two ball valves for adjusting air and water flow (Figure 1). The addition of the ball valves allows the liquid water content to be controlled while producing artificial snow. When the snow gun began operating, the cold room would warm first. Next, the cold room temperature would remain constant between -5 and $0{ }^{\circ} \mathrm{C}$ for approximately one hour for artificial snow to be produced. Compressed air of 1.5 to 3 Bar (depending on the desired LWC in snow) is mixed internally with room-temperature water flowing at a rate of approximately $1.51 \mathrm{~L}$ per minute. The mixture is forced through converging nozzles with end size of 1/16 inch. Fast moving liquid water droplets exit the nozzles and enter the walk-in freezing room, in which snow nucleation occurs. The spray pattern is conical to reduce the collision of particles within the air before they nucleate. The final mass ratio of water to air at the exit is approximately $98 \%$. Reducing the inflow of water by the adjustment valve creates drier (low LWC) snow while increasing the opening of the adjustment valve results in a high density and high LWC artificial snow. Movie S1 shows snow formation using the snow gun. A high-speed camera (OLYMPUS, i-SPEED TR, 10,000 fps) was used for capturing the slow-motion side-view videos of artificial snow particles, before impacting the surface and possibly agglomerating on it. Images of the moving snow particles were extracted from the videos and analyzed with the Image processing tool, obtaining snow particles with LWC of $\sim 22 \%$, and with diameters of $43.53 \pm 24.99 \mu \mathrm{m}$.

a)

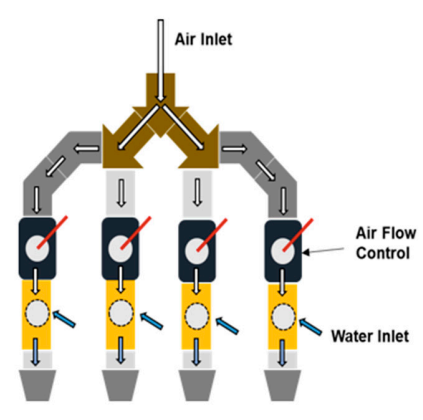

b)

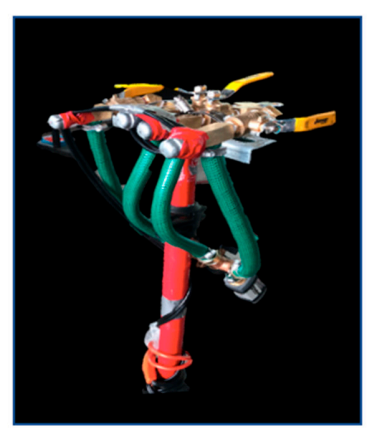

c)

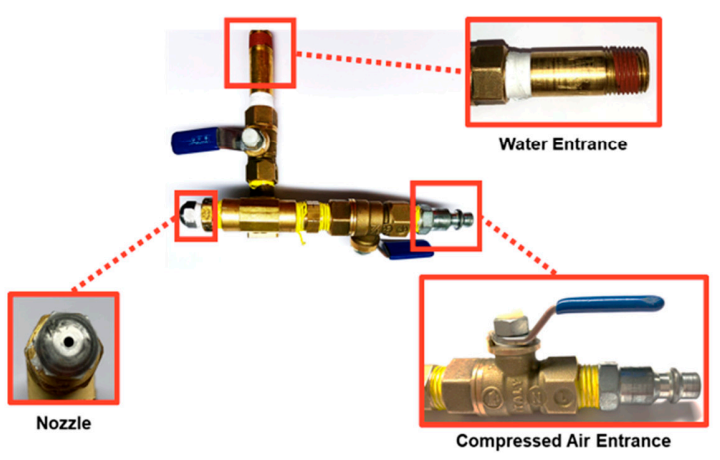

Figure 1. (a) Schematic of a snow gun with four nozzles that forms the snow by mixing air and water with controlled pressure. (b) The UToledo snow gun with four nozzles. Each nozzle has its own ball valve for controlling air and water flow. (c) The components of a single nozzle snow gun. The water entrance, compressed air entrance, and nozzle are depicted. The air and water entrance can be controlled by the corresponding ball valves, which in turn controls the LWC of snow.

LWC plays a critical role in determining snow properties. A LWC sensor was used throughout all experiments to track any changes that could occur during testing. The sensor measures the temperature and the electrical conductivity of the medium (i.e., snow). It uses a database and a complex algorithm to determine whether air, water, or snow and/or ice are present on its surface. Further details about the sensor are available in our recent patent (Figure S2) [17]. Snow consists of air, water, and ice 
and based on their ratio it can be in the pendular or funicular regime. In the pendular regime, the water droplets are surrounded by air and graupel particles and the LWC is below $\sim 27 \%$ (for a density of $0.2 \mathrm{~g} / \mathrm{cm}^{3}$ ) (Figure 2a). In the funicular regime, the air is surrounded by water and graupel particles and the LWC is high (Figure $2 b$ ). In both regimes water can migrate within the snow impacting its LWC values locally. It is hypothesized that the LWC of snow impacts its adhesion strength to any surfaces, regardless of the surface properties. Therefore, any setup to measure snow adhesion strength must prevent any water movement and change in the LWC within the snow, during the measurements. In a gravitational [27] or a centrifugal [28] setup the gradient of liquid water content occurs in snow (Figure 2c) during the adhesion measurement, leading to incorrect and unreliable correlation between LWC of snow and snow adhesion strength. Here, we utilized two LWC sensors, one on the top and another on the bottom of an inclined aluminum substrate, and visually observed migration of water to the bottom of the snowpack due to gravity (Figure 2d).

a)

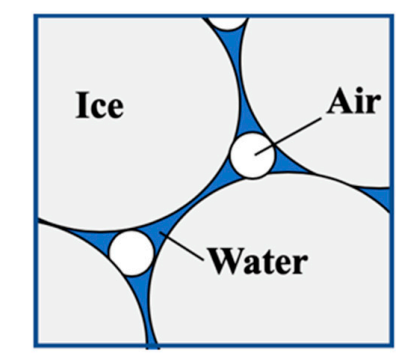

c)

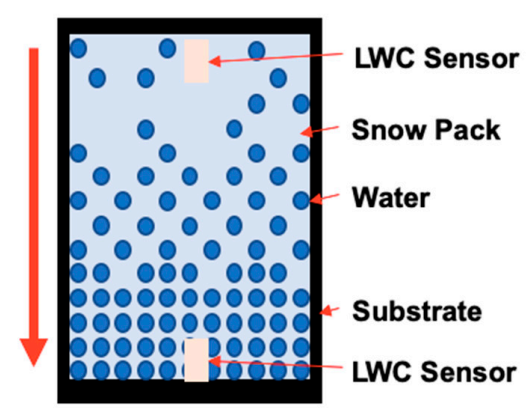

b)

Funicular

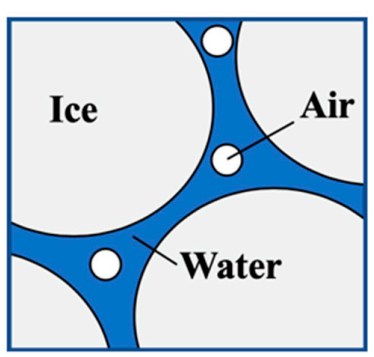

d)

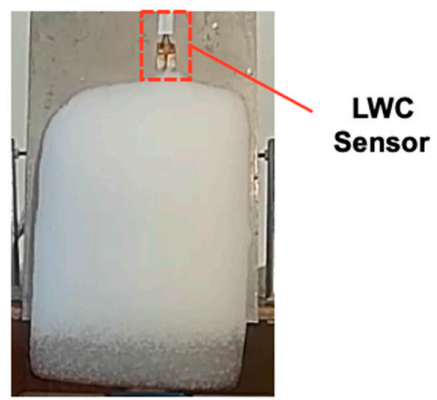

Figure 2. (a) Schematic of snow in the pendular regime; this typically occurs when the liquid water content in snow is below $\sim 27 \%$. Air and small amounts of water fill the gaps between the ice particles. (b) Schematic of snow in the funicular regime in which gaps between ice particles are mostly filled by liquid water with minimal air. At around $27 \%$ LWC in snow, the transition between pendular and funicular regimes occurs. (c) Schematically shows the liquid water content gradient that occurs in snow on an inclined substrate during shedding. The LWC sensors confirm this water movement in snow on inclined substrates. (d) A photo of a snow pile accumulated on an aluminum substrate, indicating migration of water to the bottom of the snowpack due to gravity. A liquid water content gradient forms, resulting in lower LWC at the top of the snowpack, when compared to its bottom.

To prevent the LWC gradient from rapidly changing during measurements, a flat configuration is used to design a snow adhesion measurement setup as shown schematically in Figure 3 (see also Figure S3 for the photo of the setup). An LWC sensor is centered on the sample furthest from the shear wall. Initially, two sensors were placed on the sample during testing. Once it was verified that the LWC remained unchanged, a single sensor was used to maximize the surface area of the substrate in contact with the snow. 


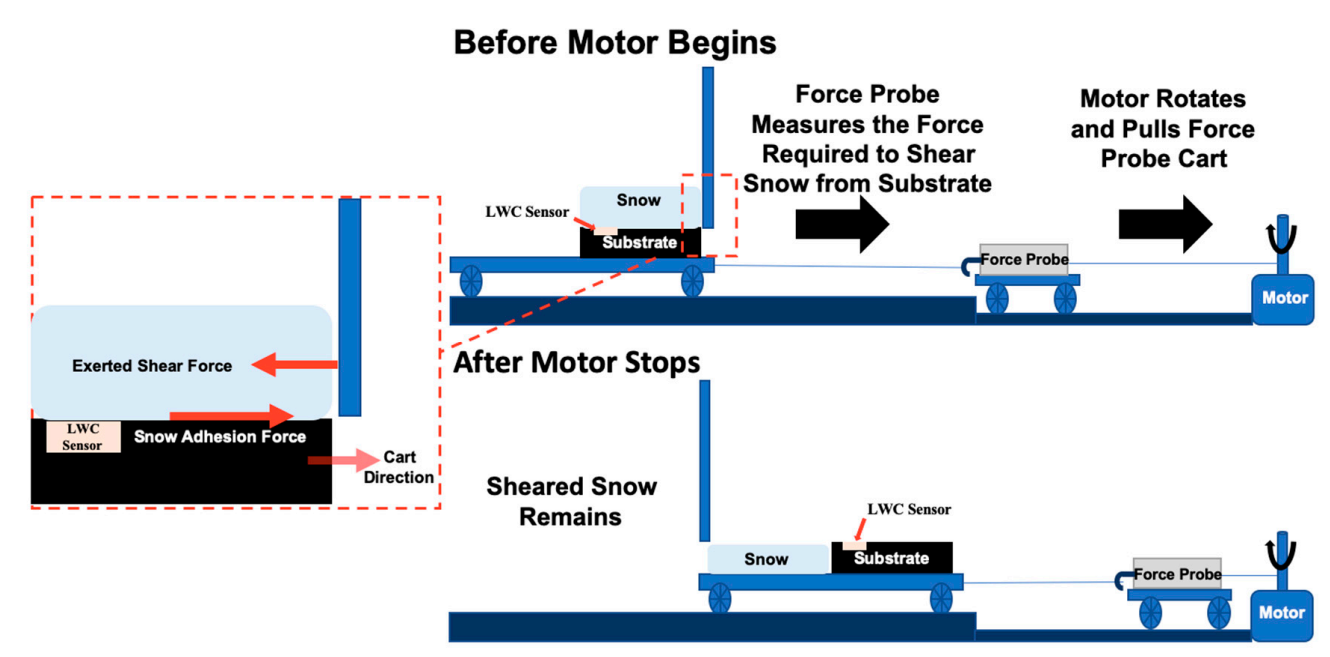

Figure 3. Schematic of a setup developed for measuring shear adhesion strength of snow on various substrates. The test substrate with snow is placed on a cart. The shear wall is adjusted to the interface of the snow and the substrate. A motor pulls a cart holding a force probe which pulls the cart with the snow sample. The force probe measures the force required to shear the snow, as well as the friction between the cart's wheels. The setup is reset to its original position and the shear wall is adjusted to not interfere with the sample or snow. The motor is turned on once more to measure the frictional force between the cart's wheels. The frictional force is measured during each experiment to account for any differences in the weight of the snow or samples.

To conduct adhesion measurements multiple $6 \times 6$ in samples made of various materials were prepared and the artificial snow formed by the snow gun was collected and sifted onto the test samples at a minimum distance of $2 \mathrm{~cm}$. The excess snow was cut from the samples using a straight edge to ensure the snow surface area was not larger than the 6 in $\times 6$ in each square sample. The sample was then placed on the test apparatus. The shear wall height was adjusted to the interface of the snow and the substrate. The motor was turned on and the cart was pulled at a speed of $1.7 \mathrm{~mm} / \mathrm{s}$. Various speeds were tested to understand how velocity impacts snow adhesion. The failure mechanisms described are apparent regardless of the cart velocity. A force probe (DS2-4 digital force gauge from GaugeCity.com) with a capacity of $20.00 \mathrm{~N}$ and a resolution of $0.01 \mathrm{~N}$ was used to measure shear forces. At the end of the first pull, the snow remained on the end of the cart, not on the test substrate. Then, the cart was reset to its initial position and the motor was turned on again. The force was recorded a second time to determine the specific friction for the test case. Because the weight of the snow changes with varying LWC, the friction test was conducted with each trial. The average friction force (it remained the same throughout the experiment) was subtracted from the maximum force recorded from the first pull with snow. The resultant is the force in newtons required to shear the snow. This resultant is divided by the area of the substrate to obtain the adhesion strength of snow in pascals (see Supporting Information). Each experiment was conducted a minimum of five times and at a temperature of $0{ }^{\circ} \mathrm{C}$ in order to mimic a realistic scenario of snow adhesion where both ice and liquid water can be present. The detailed results of the experiments are shown in Table S1. In addition, calculations of adhesion strength are shown with raw data in Figure S4 and Table S2.

To study the impact of roughness on snow adhesion strength, samples of different materials were treated with an aluminum oxide sandpaper with sizes ranging from 60- to 4000-grit. Standard stainless steel, aluminum 6061, and copper samples were used to study the impact of surface energy and roughness. In addition, high-density polyethylene (HDPE) and photovoltaic glass were purchased from Amazon and Cat I Glass Manufacturing Inc., respectively. A Keyence VHX 6000 optical microscope was used to determine the surface roughness of each material. The microscope has multi-angle observation with lighting data from every direction that enables building of 3D structures. The resolution used for the roughness measurements was 2000x. On each sample, measurements 
were taken in 16 random locations and average RMS values with error bars are reported in Table 1 . The surface energy of each sample was measured using a Kruss Mobile Surface Analyzer (MSA). The MSA uses an Owens-Wendt-Rabel \& Kaelble (OWRK) model, deionized water, and diiodomethane to calculate the surface free energy. In addition, the surface energies were also obtained by the Fowkes method using contact angle measurements of deionized water and glycerol on the test substrates.

Table 1. Surface energy measurements taken from the Kruss Mobile Surface Analyzer as well as the surface roughness measurements taken from the Keyence VHX 6000 are shown for the substrates that were tested during snow adhesion measurements.

\begin{tabular}{|c|c|c|c|c|c|}
\hline Substrate & $\begin{array}{l}\text { RMS } \\
(\mu \mathrm{m})\end{array}$ & $\begin{array}{l}\text { Polar Surface } \\
\text { Energy } \\
\left(\mathrm{mJ} / \mathrm{m}^{2}\right)\end{array}$ & $\begin{array}{l}\text { Dispersive } \\
\text { Surface Energy } \\
\left(\mathrm{mJ} / \mathrm{m}^{2}\right)\end{array}$ & $\begin{array}{l}\text { Total Surface } \\
\text { Energy } \\
\left(\mathrm{mJ} / \mathrm{m}^{2}\right)\end{array}$ & $\begin{array}{c}\text { Average Shear Adhesion } \\
\text { Strength of Snow } \\
\text { (Pa) }\end{array}$ \\
\hline \multirow{8}{*}{ AL 6061} & $7.17 \pm 0.13$ & $3.16 \pm 0.04$ & $27.13 \pm 0.26$ & $30.29 \pm 1.18$ & 29.9 \\
\hline & $15.34 \pm 0.22$ & $0.38 \pm 0.21$ & $27.71 \pm 5.06$ & $28.09 \pm 4.85$ & 187.7 \\
\hline & $134.4 \pm 0.16$ & $0.56 \pm 1.80$ & $26.59 \pm 0.12$ & $27.16 \pm 1.92$ & 151.1 \\
\hline & $169.42 \pm 1.94$ & $2.86 \pm 1.72$ & $28.46 \pm 3.12$ & $31.31 \pm 4.84$ & 137.3 \\
\hline & $238.29 \pm 1.47$ & $15.01 \pm 1.31$ & $13.77 \pm 2.91$ & $28.78 \pm 2.12$ & 51.5 \\
\hline & $273.31 \pm 2.88$ & $19.17 \pm 7.47$ & $9.44 \pm 6.44$ & $28.61 \pm 1.42$ & 50.8 \\
\hline & $308.33 \pm 2.43$ & $9.37 \pm 4.56$ & $21.58 \pm 6.01$ & $30.95 \pm 1.56$ & 32.4 \\
\hline & $36.4 \pm 1.96$ & $9.86 \pm 0.98$ & $16.34 \pm 2.74$ & $26.20 \pm 1.76$ & 331.4 \\
\hline HDPE & $36.4 \pm 4.36$ & $6.15 \pm 2.62$ & $31.03 \pm 1.37$ & $37.18 \pm 1.25$ & 29.6 \\
\hline Stainless Steel & $36.4 \pm 2.31$ & $7.41 \pm 1.85$ & $29.64 \pm 3.09$ & $37.05 \pm 4.32$ & 66.4 \\
\hline Copper & $36.4 \pm 1.34$ & $1.15 \pm 2.69$ & $34.26 \pm 0.92$ & $35.40 \pm 1.77$ & 73.3 \\
\hline
\end{tabular}

\section{Results and Discussion}

For studying snow adhesion strength to various surfaces, liquid water content (LWC) in snow plays an important role. Figure 4a shows snow shear adhesion strength to aluminum (Al 6061) and photovoltaic (PV) glass as a function of the LWC in snow. At low liquid water content values, the snow has a powdery structure and its adhesion strength is low due to the lack of free water to form capillary actions at the interface. Many air gaps can occur at the surface because the snow is dry and this can result in lower contact area between the snow and the substrate, leading to lower snow adhesion strength. As the LWC increases, the capillary forces increase, forming a strong adhesive bond between the snow and the substrate. Once the LWC in snow surpasses $\sim 20 \%$ the snow becomes slushy, and the excessive water forms a liquid layer to allow gliding of the snow grains on the substrate, leading to decrease in adhesion strength between the snow and the substrate.

a)

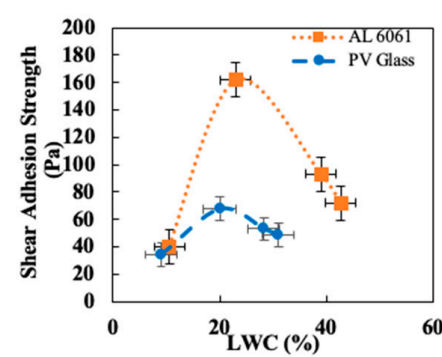

b)

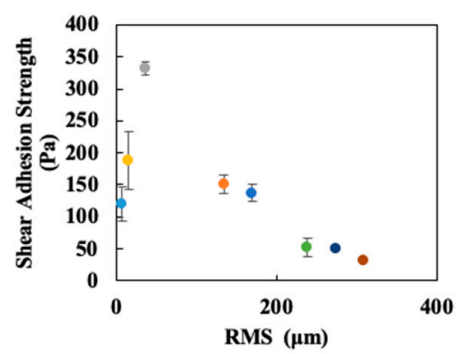

Figure 4. Impact of LWC and surface roughness on snow adhesion strength. (a) Results of snow shear adhesion strength on aluminum (Al) 6061 and photovoltaic (PV) glass. Maximum snow adhesion strength values are observed on both substrates, when the LWC of snow is around $20 \%$. (b) Results are shown for shear adhesion strength (at LWC of $\sim 22 \%$ ) of snow on aluminum 6061 substrates as a function of surface roughness (RMS $=7$ to $308 \mu \mathrm{m}$ ). 
We hypothesize that the higher snow adhesion strength of $\mathrm{Al} 6061$, when compared to the PV glass substrate, is due to differences in their roughness and surface energy. To study the impact of each parameter separately, first we treated the $\mathrm{Al} 6061$ substrates with aluminum oxide paper to obtain surfaces with various roughness. The surface roughness was measured using the Keyence VHX 6000 tool; the roughness values of the substrates are listed in Table 1. Next, we measured snow adhesion strength on these substrates, similar to the method reported earlier where the LWC in snow and substrate temperature were kept at $\sim 22 \%$ and $0{ }^{\circ} \mathrm{C}$ respectively. As mentioned earlier, the diameter of the snow particles (at LWC of $\sim 22 \%$ ) was $43.53 \pm 24.99 \mu \mathrm{m}$. While it is not possible to directly measure the size of snow particles on the surface, we hypothesize that when the substrate is very smooth (RMS values of $\sim 7.17 \mu \mathrm{m}$ or lower), snow adhesion strength is relatively low (Figure $4 \mathrm{~b}$ ). An increase in shear adhesion strength of snow is observed when the surface roughness increases to a level comparable to the size of the snow particles. The highest snow adhesion strength is observed on the $\mathrm{Al} 6061$ substrate with RMS roughness of $\sim 36.35 \mu \mathrm{m}$, where snow has more contact area with the surface, when compared to very smooth surfaces. We believe that the enhanced surface area, while maintaining the apparent surface area constant $(6 \times 6$ in), might be responsible for the observed increase in the snow adhesion strength, given the considerable presence of liquid water in snow (LWC of $\sim 22 \%$ ). As surface roughness increases further beyond the size scale of the snow particles, the surface roughness becomes filled with the snow particles, which are lubricating each other. During the adhesion measurements, cohesive failure happens locally between the bulk layer of snow and the snow particles that are filling the surface roughness. This results in reduced apparent snow adhesion strength on these very rough surfaces. However, this only can be claimed in the macroscopic level (large surface area) and not in the microscopic level. Figure 5a-c schematically demonstrates the impact of surface roughness on the adhesion strength of snow.

a)

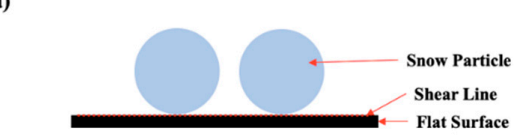

b)
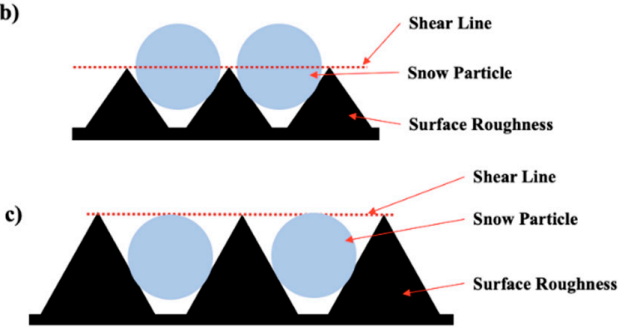

Figure 5. Impact of surface roughness on the snow adhesion mechanism, hypothesized schematically. (a) On a very flat surface, snow does not become trapped within the roughness and shears at the interface. (b) When the size of snow particles and surface roughness are on the same range, the snow particle are sheared in half, leading to enhanced adhesion strength values. (c) When the snow particles are smaller than the surface roughness, shear adhesion strength is lower because some snow particles glide over others that are inside the roughness.

Surface energy is another important parameter when studying snow adhesion strength. Since snow is composed of liquid water, ice, and air, it is a polar structure with a surface energy of 30-72 mN/m, depending on its LWC value [29]. To understand the impact of surface energy, aluminum 6061, stainless steel, HDPE, and copper were studied. It is important to note that the aluminum used in this experiment was pretreated to prevent oxidation of pure aluminum to form $\mathrm{Al}_{2} \mathrm{O}_{3}$. This pretreatment of the metal results in lower surface energy than the pure element [30]. Each substrate was roughened using aluminum oxide sandpaper to obtain the same average roughness (RMS of $\sim 36.4 \mu \mathrm{m}$ ) before adhesion measurements. In addition, for the adhesion measurements on all substrates, the LWC of snow 
and the substrate temperature were kept at $\sim 22 \%$ and $0{ }^{\circ} \mathrm{C}$, respectively. A strong correlation was found between polar and dispersive surface energy and snow shear adhesion strength.

Dispersive surface interactions are caused by temporary fluctuations of charges between atoms or molecules. These temporary interactions exist in every substance and are known as Van der Waals interactions with a shear adhesive strength of $0.4-4.0 \mathrm{~kJ} / \mathrm{mol}$. Polar interactions are comprised of Coulomb interactions between dipoles (e.g., hydrogen bonds). Hydrogen bonding has a shear adhesive strength range of $12-30 \mathrm{~kJ} / \mathrm{mol}$, which is much stronger, compared to the der Waals interactions [31]. Modulating surface roughness impacts the polar and dispersive surface energy while maintaining the same total surface energy (Table 1). Dispersive surface energies are naturally weak. Polar surface energy is related to hydrogen bonding and Coulombic forces, which are stronger than the Van der Waals forces. For highly nonpolar surfaces, variation in dispersive surface energy greatly impacts the adhesive strength. However, when the surface is relatively polar, the component of the dispersive surface energy does not play a major role in determining the adhesion strength of the surface to another material, i.e., snow. For a relatively polar surface, by decreasing the polarity, the adhesion strength of snow decreases as well (Table 1). To decrease surface polarity the symmetry of the surface roughness must increase. These findings help in designing surfaces with reduced snow adhesion strength.

While conducting snow adhesion measurements, three snow de-adhering/shedding mechanisms were identified (Figure S5). LWC was held constant at $\sim 22 \%$ for the observation of each failure mechanism. Slight adjustments in the compressed air pressure and water flow rate of the snow gun as well as the freezing room temperature enables modulating the LWC of the created artificial snow. Once the snow is on the substrate, the variation of liquid water movement in snow depends heavily on the freezing room temperature. This temperature was adjusted slightly while the LWC values were recorded using the sensor to ensure that the LWC was constant during the adhesion measurements. Figure $6 \mathrm{~b}$ shows a complete compression which occurs when substrate temperatures are above $2{ }^{\circ} \mathrm{C}$ during snow de-adhesion/shedding. At these temperatures there is minimal ice in snow and the snow-substrate interface contains considerable liquid water. Therefore, snow begins de-adhering/shedding by forcing each snow particle into the next, resulting in a rolling motion of the snow (see Movie S2). When temperature drops to below freezing (i.e., at $-2{ }^{\circ} \mathrm{C}$ ) the snow de-adhering/shedding mechanism turns to bulk sliding (see Movie S3). A quasi-ice layer forms at the snow and substrate interface, shown in Figure 6a, allowing the snowpack to remain in one piece during shedding. In the sliding de-adhering/shedding mode, the snow shear adhesion strength is very high, when compared to the compression mode; this might be due to partial formation of ultrathin ice at the snow-substrate interface [27]. A combined compression-sliding snow de-adhering/shedding mode is observed when the substrate temperature is around $0{ }^{\circ} \mathrm{C}$ and is shown in Figure $6 \mathrm{c}$. In this mode, snow compression occurs at the beginning of the adhesion test and then changes to a sliding mode, where the substrate temperature $\left(\sim 0^{\circ} \mathrm{C}\right)$ is favorable for the combined presence of liquid water and ice at the snow-substrate interface [27]. In this mode, the snow may compress, then slide, and repeat, or vice versa (see Video S4 and Figure S6).

a)

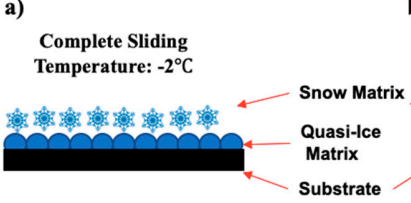

b) c) Temperature: $2^{\circ} \mathrm{C}$

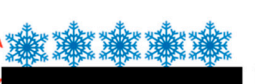

c) Temperature: $0^{\circ} \mathrm{C}$

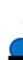

Figure 6. (a) Depicts the snow-substrate interface in snow sliding de-adhering/shedding mode, in which the snowpack slides as a whole (one piece) without any deformation of the snowpack or rolling of snow particles. (b) Depicts the snow-substrate interface in snow compression de-adhering/shedding mode, in which snow particles roll and the snowpack deforms in shape. (c) A combined sliding-compression mode in which snow compression occurs at the beginning of the adhesion test and then changes to a sliding mode, where substrate temperature is $0{ }^{\circ} \mathrm{C}$, favorable for the combined presence of liquid water and ice at the snow-substrate interface. 
To confirm the infiltration of liquid water in snow in relation to surface roughness, and to verify our hypothesis on the impact of temperature on snow adhesion strength at rough surfaces, we examined the surface roughness during the adhesion measurement [32]. Figure $7 \mathrm{a}-\mathrm{d}$ shows the liquid infiltration progression, in which the free water completely fills all gaps in the roughness. In Figure 7a, water is just above the substrate roughness. As time progresses, water begins to infiltrate the surface roughness, shown with the white dashed line in Figure $7 \mathrm{~b}-\mathrm{d}$. The arrow shows the front of the water progressively moving into the surface roughness. When temperatures are above freezing, this infiltrated liquid allows the snow to glide off. However, when temperatures drop below freezing, the infiltrated liquid freezes, creating a strong anchoring effect and increasing the shear adhesion strength. During experiments, ice formed faster on higher roughness materials than on lower roughness materials. Therefore, reducing the roughness will result in a reduced shear adhesion strength of snow at subzero temperatures, because there will be less contact area for ice to form between the liquid water and the substrate. Furthermore, as surface roughness increases, due to increased surface area between snow and surface, the snow layer loses energy in higher rates, leading to a faster formation of ice at the interface.

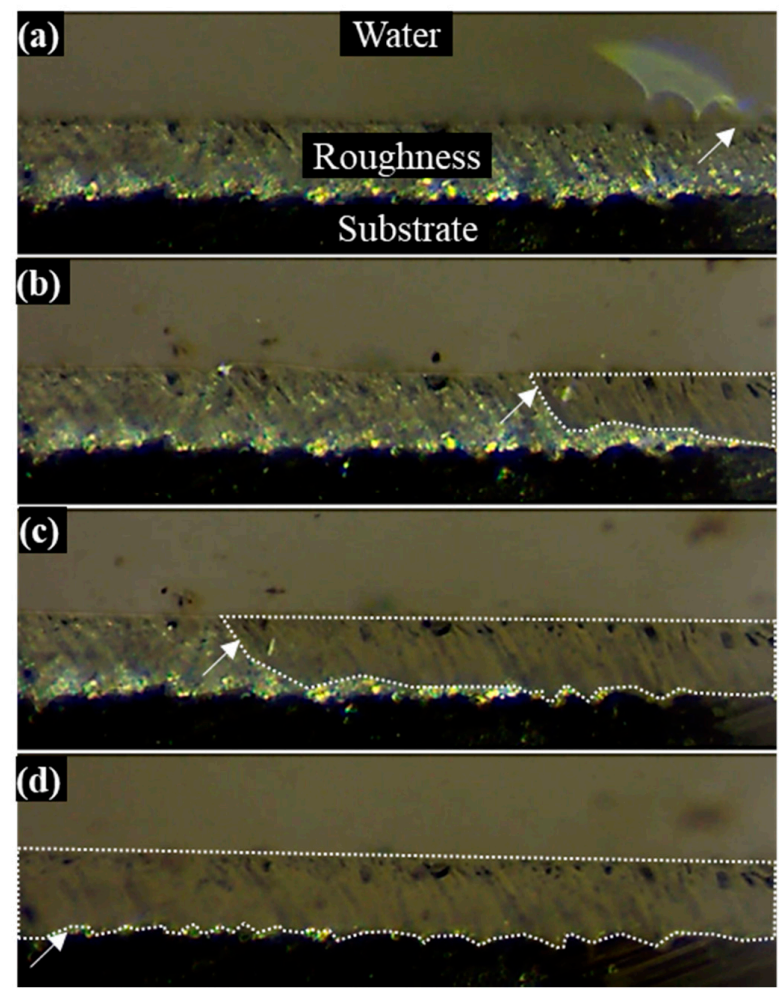

Figure 7. (a-d) The time progression of the liquid layer in snow (LWC $22 \%$ ) infiltrating the surface roughness $(\mathrm{RMS}=36.4 \mu \mathrm{m})$ of $\mathrm{Al} 6061$ substrate at a substrate temperature of $2{ }^{\circ} \mathrm{C}$ : $(\mathbf{a})$ Water is above the surface roughness. (b) As time progresses, the water begins to seep into the roughness, shown with a dashed white line. (c) Water continues to flow into the surface roughness until (d) the roughness is completely infiltrated with water. The arrow in each section shows the front of the water progressively moving into the surface roughness. After liquid water infiltration, when temperatures rise above the freezing point, this liquid layer results in snow gliding on rough surfaces with reduced shear adhesion strength; however, post infiltration, when temperatures go below freezing point, the liquid layer forms a thin ice layer at the snow-substrate interface, leading to enhanced snow shear adhesion strength.

\section{Conclusions}

A non-destructive apparatus was developed to accurately measure the shear adhesion strength of snow without changings its properties (i.e., liquid water content) during the measurement. The setup involved using a surface-mountable sensor to monitor the liquid water content in snow and its 
temperature during experiments. An internal mixing snow gun was also developed that includes ball valves to control air and water flow to the mixing chamber for snow formation with controlled liquid water content. To the best of our knowledge, this is closest attempt in forming artificial snow comparable to natural snow, considering the limited size of our freezing room and the lack of temperature gradients that real snow experiences falling from the atmosphere.

We report that shear adhesion strength of snow peaks near $20 \%$ liquid water content when the substrate temperature is at $0{ }^{\circ} \mathrm{C}$. At lower than $\sim 20 \% \mathrm{LWC}$, snow is powdery with little free liquid water content to form capillary action, leading to low snow adhesion strength. As the LWC increases to around $20 \%$, a strong adhesive bond is formed by capillary forces at the interface. This strong bond begins to diminish as the snow becomes slushy and a thin layer of water forms at the interface and allows sliding action to occur, when the LWC is greater than $20 \%$.

We also found that when surface roughness nears the size of the snow particles, the shear adhesion strength of snow is maximum due to the enhanced surface area between the snow and the substrate. As the roughness increases, snow adhesion strength decreases because multiple lubricating snow particles can fit inside the roughness, resulting in local cohesive failures in snow which are much weaker than adhesive failures. We also show that reducing the surface polarity leads to lower snow adhesion strength.

Finally, we report three snow shedding/de-adhering mechanisms depend on the temperature during the adhesion measurement. At temperatures below $-2{ }^{\circ} \mathrm{C}$ a quasi-ice layer forms at the interface, allowing for the snow mass to shed in one piece. At temperatures above $2{ }^{\circ} \mathrm{C}$ a liquid layer forms at the interface, allowing for lower shear adhesion strength and a compressive failure mechanism. Between -2 and $2{ }^{\circ} \mathrm{C}$, a combination of the two failure mechanisms occurs, such that an ice layer and liquid layer may form at different locations on the substrate. The different interface layers allow for the combination of the two failure mechanisms to occur on the same substrate.

In conclusion, adding the liquid water content sensor allowed for tracking the temperature and wetness of the snow throughout the adhesion experiments. The ability to ensure constant liquid water content and temperature profiles throughout the experiments allowed for failure mechanisms to be explored. It also enabled determining the impact of surface properties on snow shear adhesion strength. Overall, the development of the snow gun that enabled snow formation with controlled LWC and the non-destructive snow adhesion apparatus along with new findings of snow failure mechanisms will aid future works in developing new surfaces to mitigate snow accumulation.

Supplementary Materials: The following are available online at http://www.mdpi.com/2076-3417/10/16/5407/s1, Figure S1: Walk-in Freezing Room, Figure S2:Schematic of the LWC sensor, Figure S3: Photo of the snow adhesion measurement setup, Figure S4: Representative plots of force values obtained from force probe, Figure S5: Plot of shear adhesion strength of snow as a function of dispersive surface energy, Figure S6: Time progression of snow shear adhesion failure mechanisms, Figure S7: Liquid layer formation at snow-substrate interface, Table S1: Experimental results of snow shear adhesion testing, Table S2: Calculation of average instantaneous shear adhesion strength values, Video S1: Snow gun operation, Video S2: Complete compression failure mechanism, Video S3: Complete sliding failure mechanism, Video S4: Combination of sliding and compression failure mechanisms, Video S5: Failure mechanisms side by side.

Author Contributions: Conceptualization, H.S.; data curation, J.H.; formal analysis, J.H.; investigation, J.H., B.M., M.S., K.B. and H.S.; methodology, J.H., B.M., M.S., K.B. and H.S.; project administration, H.S.; resources, H.S.; supervision, H.S.; visualization, J.H. and B.M.; writing —original draft, J.H.; writing-review and editing, B.M. and H.S. All authors have read and agreed to the published version of the manuscript.

Funding: This research received no external funding.

Acknowledgments: The authors thank Douglas Nims, Department of Civil and Environmental Engineering, University of Toledo for providing inputs to the manuscript.

Conflicts of Interest: The authors declare no conflicts of interest. 


\section{References}

1. Organization, I.S. Atmospheric Icing of Structures; International Organization for Structures (ISO): Geneva, Switzerland, 2001; Volume 12494.

2. Farzaneh, M. Atmospheric Icing of Power Networks; Springer Science \& Business Media: Berlin/Heidelberg, Germany, 2008.

3. Kleissl, K.; Georgakis, C. Bridge ice accretion and de- and anti-icing systems: A review. In Proceedings of the 7th International Cable Supported Bridge Operators' Conference, New York, NY, USA, 26-27 August 2019; pp. 161-167.

4. Makkonen, L. Models for the growth of rime, glaze, icicles and wet snow on structures. Philos. Trans. R. Soc. Lond. Ser. A Math. Phys. Eng. Sci. 2000, 2913, 131211051. [CrossRef]

5. Sojoudi, H.; Arabnejad, H.; Raiyan, A.; Shirazi, S.A.; McKinley, G.H.; Gleason, K.K. Scalable and durable polymeric icephobic and hydrate-phobic coatings. Soft Matter 2018, 14, 3443-3454. [CrossRef]

6. Admirat, P. Wet Snow Accretion on Overhead Lines. In Atmospheric Icing of Power Networks; Springer Science and Business Media LLC: Berlin/Heidelberg, Germany, 2008; pp. 119-216.

7. Raiyan, A.; McLaughlin, T.S.; Annavarapu, R.K.; Sojoudi, H. Effect of superamphiphobic macrotextures on dynamics of viscous liquid droplets. Sci. Rep. 2018, 8, 15344. [CrossRef]

8. Mohammadian, B.; Sarayloo, M.; Abdelaal, A.; Raiyan, A.; Nims, D.K.; Sojoudi, H. Experimental and theoretical studies of wet snow accumulation on inclined cylindrical surfaces. Model. Simul. Eng. 2020, 2020, 1-11. [CrossRef]

9. Mohammadian, B.; Sarayloo, M.; Heil, J.; Sojoudi, H.; Robertson, M.; Hong, H.; Tran, T.; Patil, S.; Krishnan, V. Prevention of snow accretion on camera lenses of autonomous vehicles. SAE Tech. Pap. Ser. 2020, 1, 1-9.

10. Hong, H.; Bathusha, M.R.; Patil, S.; Mohammadian, B.; Krishnan, V.; Fountain, M.; Sojoudi, H. Numerical investigation of snow accumulation on a sensor surface of autonomous vehicle. SAE Tech. Pap. Ser. 2020, $1,1-9$.

11. Burnham, L.; Riley, D.; Walker, B.; Pearce, J.M. Performance of Bifacial Photovoltaic Modules on a Dual-Axis Tracker in a High-Latitude, High-Albedo Environment. In Proceedings of the IEEE 46th Photovoltaic Specialists Conference (PVSC 2019), Chicago, IL, USA, 16-21 June 2019; pp. 1320-1327.

12. Andenæs, E.; Jelle, B.; Ramlo, K.; Kolås, T.; Selj, J.; Foss, S.E. The influence of snow and ice coverage on the energy generation from photovoltaic solar cells. Sol. Energy 2018, 159, 318-328. [CrossRef]

13. Andersson, P.-O.; Jelle, B.P.; Zhang, Z. Passive snow repulsion: A state-of-the-art review illuminating research gaps and possibilities. Energy Proc. 2017, 132, 423-428. [CrossRef]

14. Kemp, A.K. The formation of ice on electrical conductors during heavy falls of wet snow. Cold Reg. Sci. Technol. 1980, 17, 83-88.

15. Makkonen, L. Estimation of wet snow accretion on structures. Cold Reg. Sci. Technol. 1989, 17, 83-88. [CrossRef]

16. Libbrecht, K.G. The physics of snow crystals. Rep. Prog. Phys. 2005, 68, 855-895. [CrossRef]

17. Abdelaal, A.; Sarayloo, M.; Nims, D.; Sojoudi, H. Sensor for Detection and Measurement of Ice, Snow and Liquid Water Content (LWC) and Methods of Using Same. U.S. Patent 62/809,863, 4 October 2019.

18. Denoth, A. The pendular-furnicular liquid transition and snow metamorphism. J. Glaciol. 1982, $28,357-364$. [CrossRef]

19. Dalle, B.; Admirat, P. Wet snow accretion on overhead lines with French report of experience. Cold Reg. Sci. Technol. 2011, 65, 43-51. [CrossRef]

20. Likitkumchorn, N. Ice Prevention and Weather Monitoring on Cable-Stayed Bridges. Master's Thesis, University of Toledo, Toledo, OH, USA, 2014.

21. Makkonen, L.; Wichura, B. Simulating wet snow loads on power line cables by a simple model. Cold Reg. Sci. Technol. 2010, 61, 73-81. [CrossRef]

22. Finstad, K.J. Accreted Snow Loads; U.S. Army Cold Regions Research and Engineering Laboratory: Hanover, NH, USA, 1998.

23. Sojoudi, H.; Wang, M.; Boscher, N.; McKinley, G.H.; Gleason, K.K. Durable and scalable icephobic surfaces: Similarities and distinctions from superhydrophobic surfaces. Soft Matter. 2016, 12, 1938-1963. [CrossRef]

24. Sojoudi, H.; McKinley, G.H.; Gleason, K.K. Linker-free grafting of fluorinated polymeric cross-linked network bilayers for durable reduction of ice adhesion. Mat. Horizons 2015, 2, 91-99. [CrossRef] 
25. Yukiko Mizuno, G.W. Experimental Studies on Snow Accretion at Subzero Temperatures. Int. Glaciol. Soc. 1983, 1, 209-210.

26. Annavarapu, R.K.; Kim, S.; Wang, M.; Hart, A.J.; Sojoudi, H. Explaining evaporation-triggered wetting transition using local force balance model and contact line-fraction. Sci. Rep. 2019, 9, 405. [CrossRef]

27. Saito, H.; Takai, K.; Takazawa, H.; Yamauchi, G. A study on snow sticking weight to water-repellent coatings. J. Soc. Mat. Sci. 1997, 46, 216-219. [CrossRef]

28. Hefny, R.; Kollar, L.E.; Farzaneh, M.; Payrard, C. Adhesion of Wet Snow to Different Cable Surfaces. In Proceedings of the 13th International Workshop on Atmospheric Icing of Structures, Andermatt, Switzerland, 8-11 November 2009.

29. Ketcham, W.M.; Hobbs, P.V. An experimental determination of the surface energies of ice. Philos. Mag. J. Theor. Exp. Appl. Phys. 1969, 19,1161-1173. [CrossRef]

30. Ajersch, G.K.F. Surface energy and chemical characteristics of interfaces of adhesively bonded aluminium joints. J. Mat. Sci. 1994, 29, 676-681.

31. Garrett, R.H.; Grisham, C.M. Part I: Molecular components of cells. In Biochemistry; Belmont Publications Inc.: Santa Ana, CA, USA, 1996; pp. 1-375.

32. Sojoudi, H.; Kim, S.; Zhao, H.; Annavarapu, R.K.; Mariappan, D.; Hart, A.J.; McKinley, G.H.; Gleason, K.K. Stable wettability control of nanoporous microstructures by icvd coating of carbon nanotubes. ACS Appl. Mat. Interfaces 2017, 9, 43287-43299. [CrossRef]

(C) 2020 by the authors. Licensee MDPI, Basel, Switzerland. This article is an open access article distributed under the terms and conditions of the Creative Commons Attribution (CC BY) license (http://creativecommons.org/licenses/by/4.0/). 